\title{
Latest Advances in DTC Control of Induction Motors
}

\author{
Sudharani Potturi, Rajashekar P. Mandi
}

\begin{abstract}
In these days, developments in the area of Induction Motor control is increasing significantly. Considerable advancements have been taken place in the area of Direct Torque Control (DTC), which is capable of providing quick dynamic response with respect to torque and flux. This paper presents a detailed survey on various latest techniques of DTC control of Induction Motor such as DTC-SVM with hysteresis band, DTCSVM with Model Predictive Control, DTC with sliding mode control, DTC with Model reference adaptive system (MRAS) et cetera. The simulation results are discussed for DTC-SVPWM topology and results obtained proves that this method has reduced torque ripple
\end{abstract}

Keywords: Induction Motor, DTC, SVM, Predictive Control, MRAS, sliding mode et cetera.

\section{INTRODUCTION}

I nduction Motors are playing a consequential role as Industrial motor due to its rugged construction, easy maintenance and less cost. Hence it is essential to develop an efficient speed control strategy especially for variable speed applications. There are various speed control methods are already been developed and proposed by many authors such as V/f control, Field oriented control, DTC, etc. With DTC control it is possible to achieve direct control of torque and flux is possible [1]. In case of DTC control coordinate transformation is not necessary. And also it gives minimal block response time compared to vector control, Basic principle of DTC and its various control strategies proposed by various authors in the recent years are discussed in the following sections.

\section{PRINCIPLE OF DTC}

Fig. 1 gives the the basic hysteresis based DTC[1] that consists of two independent loops of torque and stator flux.The actual values of the stator flux and torque are compared with the reference values and the errors are fed to the respective hysteresis controllers. The outputs of hysteresis controllers along with the position of stator flux is fed to the look up table to enable the corresponding switching action. The output voltage of the inverter is varied according to the switching action to correct the errors. DTC allows the inverter switches to operate at variable switching frequencies.

Along with the advantages this type of DTC strategy suffers certain drawbacks, such as i. Sluggish response during starting and changing the load; ii. No discrimination

between small and large errors in flux and torque during start up, step changes and steady state; iii. High switching losses. To overcome these drawbacks, there can be various solutions [5] such as use of non intelligence tables, predictive algorithms, fuzzy logic based systems [10].

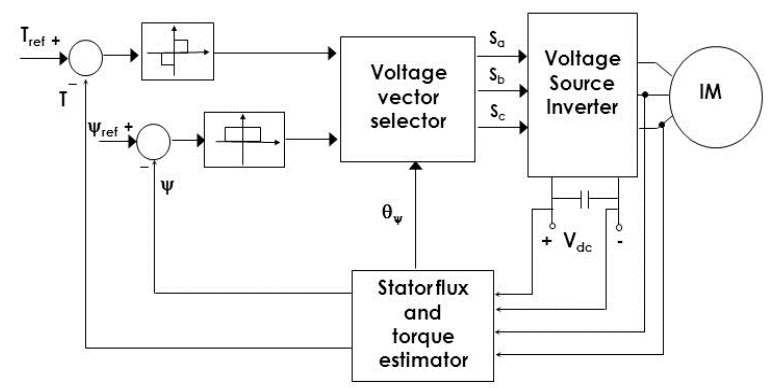

Fig. 1. Block diagram of DTC control

\section{DTC STRATEGIES}

\section{A. DTC with Flux optimization algorithm}

A new algorithm is proposed [2] to minimize the losses in the Induction Motor by calculating the optimized d-axis current given by

$$
i_{\text {dsoptimum }}=\sqrt[4]{\frac{y}{x}\left(\frac{T e}{k}\right)^{\wedge} 2}
$$

Fig. 2 gives the schematics of DTC control incorporated with flux optimization algorithm. In this method the calculated value of the flux is compared with the optimized value of the flux (determined by the optimized current from Equation (1) instead of reference value [1] and errors are processed to generate the switching pulses.

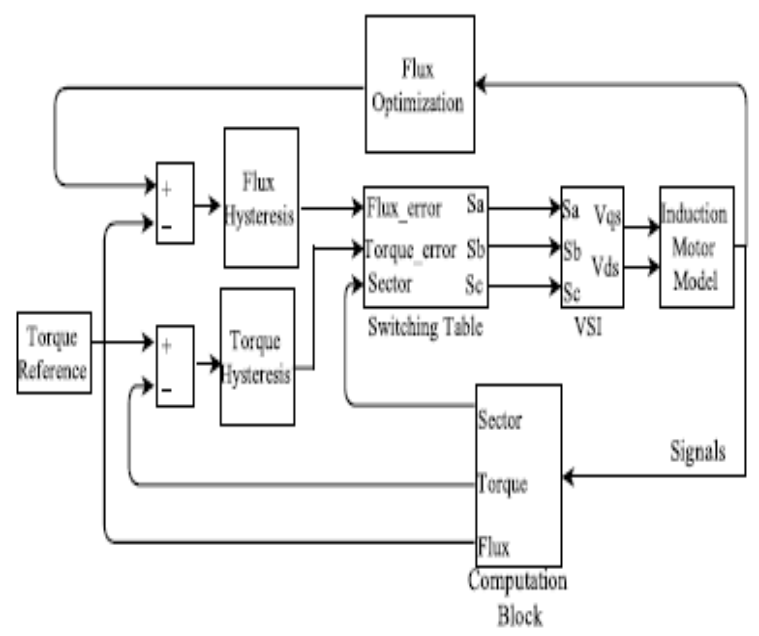

Fig. 2. DTC with flux optimization

Revised Manuscript Received on March 5, 2020.

Mrs. Sudharani Potturi , Ph.D in the field at REVA University.

Dr. Rajashekar P. Mandi, Director, School of Electrical and Electronics Engineering, REVA University.

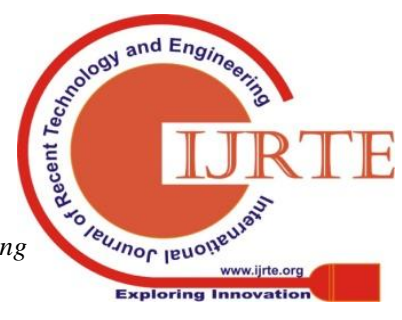


With this scheme, the torque ripple can also be reduced along with loss minimization. The MATLAB/SIMULINK results of $15 \mathrm{HP}$ Induction Motor presented in [2] shows that an efficiency of $87 \%$ can be achieved.

\section{B. DTC with Instantaneoous Voltage Control}

Since the magnitude of torque ripple and inverter switching frequency are inversely proportional, in order to decrease the torque ripple it is essential to increase switching frequency, which leads to high switching losses. This can be overcome with DTC -SVM strategy along with instantaneous voltage control which is also known as Kim-Sul algorithm [6]. In this method rotor position information is not necessary and hence it is easy to implement.

In [7] a new DTC method is proposed for a 5-Phase Induction motor. The simulation results of various responses such as torque, speed, FFT analysis are presented. The FFT analysis of hysteresis band based DTC method shows that as the speed increases, the presence of distributed harmonics shifts towards fundamental component. Whereas in this proposed scheme, the ripple distribution is independent of variation in speed as switching frequency remains constant.



Fig. 3. DTC-SVM based on instantaneous voltage control With the proposed algorithm a THD of $5.16 \%$ is achieved [7] with fundamental frequency of $25 \mathrm{~Hz}$.

\section{DTC with MRAS and Luenberger Algorithm}

In [13], a sensor less AC drive operation is discussed using MRAS(Model Reference Adaptive System) [12] and Luenberger algorithms. The challenges behind the usage of sensor for precise reading and estimation of Motor speed can be avoided by making the drive system as sensor less. Open loop estimation of speed can be carried out by different methods such as MRAS, Luenberger algorithm, Kalman filter, signal injection et cetra. A comparative study of MRAS and Luenberger observer is presented using MATLAB/SIMULINK and also dSPASE ds 1103 platforms.

In case of MRAS, the flux calculation is done using two parallel models and the outputs of these two are compared and based on the difference value the estimated parameter is adjusted. Where as in Luenberger algorithm, the angular speed of the rotor is calculated by duplicating the real system to correct its states based on the real system output negative feedback. Fig. 4 presents the proposed system in which both MRAS and Luenberger observers work independently.



Fig. 4. MRAS and Luenberger observer based DTC control.

The tests are performed on a 4-pole, $5.5 \mathrm{~kW}$ Induction motor and is observed that MRAS is giving accurate results for speeds greater than 100rpm and Luenberger Observer is giving accurate results above $35 \mathrm{rpm}$. Hence there is a limit on the minimum operating speed.

\section{Sliding Mode DTC (SMDTC)}

Sliding Mode approach [4] to DTC control guarantees good dynamic response, robustness and stability for a specified range of variations in the controlled quantities [10]. In general, sliding mode approach for DTC consists of observer for determination of stator or rotor flux, torque and rotor speed.

In [4], an Integrated Sliding Mode DTC (ISMDTC) is proposed, which consists of two regulators for speed and flux (Fig. 5).



Fig. 5. Schematic of ISMDTC

The SMO block estimates stator-flux and torque by taking dc bus voltage and two line currents. This calculation is independent of rotor speed. The authors [4] presented the design of the ISMDTC controller in detail aloong with the comparative study of classical DTC and ISMDTC. The results were obtained for $400 \mathrm{~V}, 50 \mathrm{~Hz}, 0.75 \mathrm{~kW}$ Induction motor which is fed by a VSI with SVPWM. The proposed model guarentees the better performance by showing the less errors in case of estimated electromagnetic torque and stator flux.

\section{E. DTC with dither signal injection}

Classical DTC of Induction motor experiences stator flux demagnetization at low speeds. 
To neutralize this demagnetization effect of stator flux, a sinusoidal dither signal of minute magnitude is injected in the hysteresis controllers (error blocks) [8]. This injection is done for both flux and torque bands. In [8], the authors discussed the advantages of dither signal injection. A detailed study of current and flux ripple with and without dither signals is presented for 3-level VSI fed Induction Motor. The main drawback of this method is, by the injection of dither, the switching frequency of the inverter increases, there by the increase in switching losses.

\section{F. DTC with Model Predictive Solution}

In case of predictive control, the status of control variable is computed and appropriate controller action is executed with out any time delay (Fig. 5). This model makes use of model predicitive solution [3], (which involves prediction of troque and stator flux) for compensating the flux and torque errors in DTC method. The proposed method consiists of two additional stages after calculating the torque and flux values and error calculations of the same.

In the first stage, proper voltage vector is chosen based on switching table to compensate flux and torque errors. If the estimated torque is equal to reference torque, the active voltage vector is chosen instead of zero vector in contrast to the classical DTC. In the second stage, the selected active voltage vector, " $V n$ " is sub divided into number of sub divisions like " $m$ ", $(k / m)$. Vn. Where $k=1,2, \ldots . m$. Several vectors with same direction and different duty cycles are obtained from voltage vector. Then, stator flux and torque will be predicted for the new voltage vectors as well as the zero voltage vector for the next sampling period $k+1$.

Since the selected vector and its subdivisions have definite direction, to compensate flux error, a simple cost function with single variable (torque) could satisfy the control strategy requirements and the flux variable is included as a constraint in the cost function. This method involves complex implemetation even though it achieves good dynamic response.

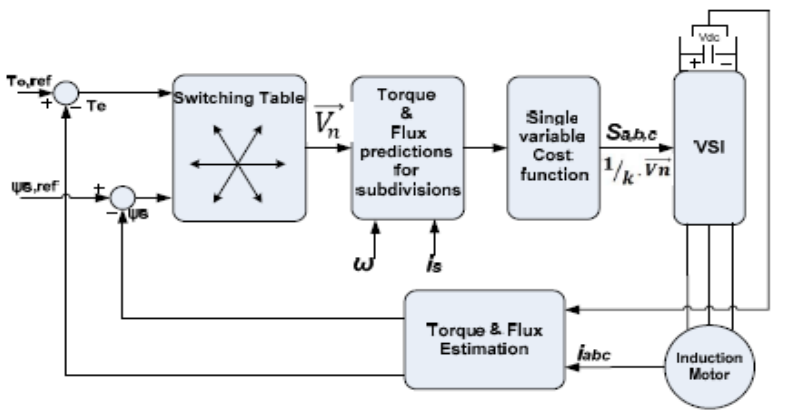

Fig. 6. DTC with Model Predictive Solution

\section{G. DTC-SVPWM}

The drawbacks with hysteresis comparator such as dynamic resonant excitement in the load due to variable switching frequencies, current and flux distortions due to sector change can be overcome by DTC-SVM strategy[12]. It is also possible to avoid the look up table in selecting the vectors. Fig 7 shows the block diagram of DTC- SVPWM .

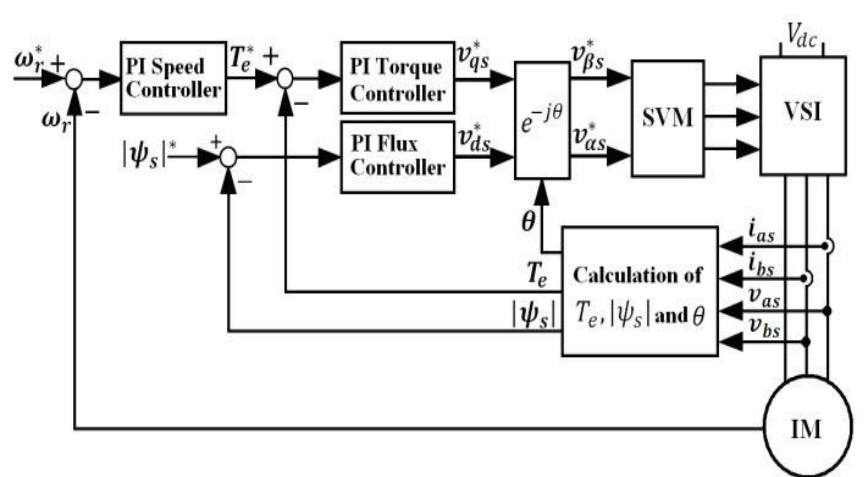

Fig. 7. Block diagram of DTC-SVM

Two PI controllers are used for both flux and torque respectively to produce reference voltage vector. Based on these two reference voltages and flux angle, the gating signals are generated for VSI. When compared to the traditional DTC, in case of the proposed DTC based on SVM the torque and flux ripples were reduced as given in the Table $-\mathrm{I}$

TABLE-I COMPARISON OF RIPPLE FACTOR DTC \& SVM-DTC

\begin{tabular}{|l|l|l|}
\multicolumn{2}{l|}{ [4] } \\
\hline Scheme & Flux Ripple & Torque Ripple \\
\hline DTC & $10.015 \%$ & $19.027 \%$ \\
\hline DTC-SVM & $4.889 \%$ & $8.539 \%$ \\
\hline
\end{tabular}

The above results were achieved under constant flux and variable load conditions. Remote control operation can be achieved by implementing the Internet of Things based Control.

The schematics of DTC with space vector pulse width modulation and the sub system of DTC are presented in Fig. 8 and Fig. 9 respectively.

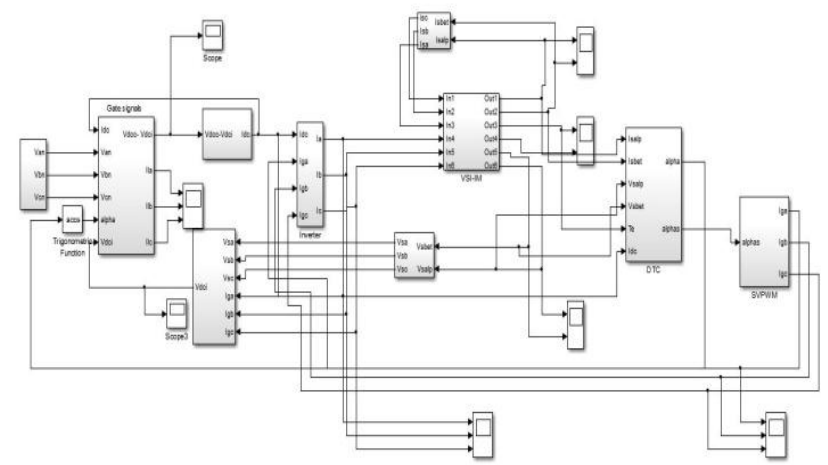

Fig. 8. Simulink Model of DTC SVPWM

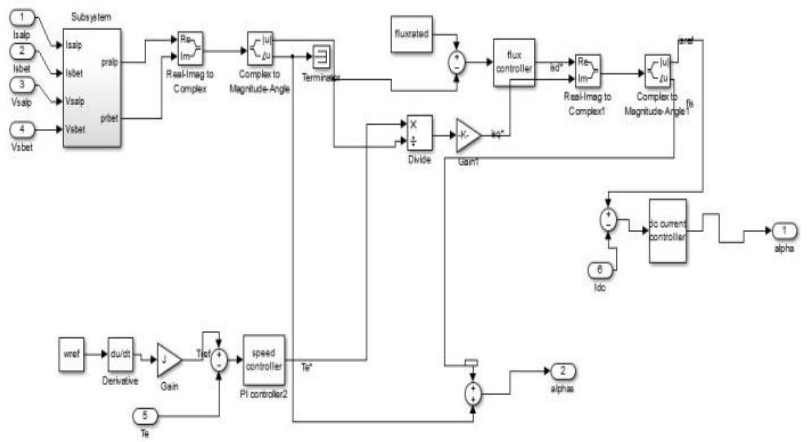

Fig. 9. Simulink Model of DTC

The simulation is performed with a reference torque of 5 $\mathrm{N}-\mathrm{m}$ and speed of 500rpm. 
The torque reached the reference value at less than $3 \mathrm{sec}$ and a speed of $470 \mathrm{rpm}$ is achieved as shown in Fig.10. Fig .11 shows that minimum and maximum values of torque distortions are between $5.04 \mathrm{~N}-\mathrm{m}$ and $4.93 \mathrm{~N}-\mathrm{m}$ and a ripple percentage of $2.2 \%$ is achieved which proves that the results produced in this paper are better than existing models [12].

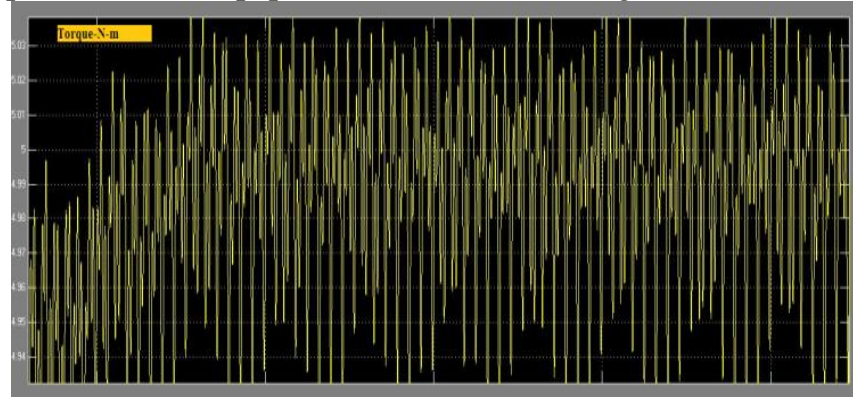

Fig. 10. Torque ripple for a load torque of $5 \mathrm{~N}-\mathrm{m}$

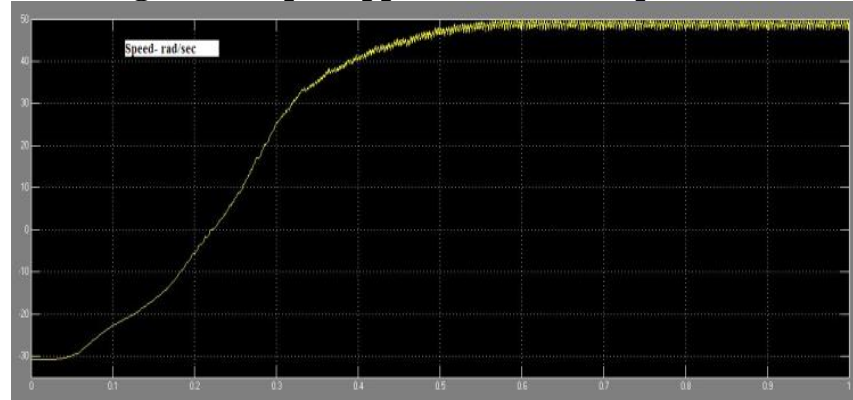

Fig. 11. Speed in rad/sec

\section{CONCLUSION}

This paper discussed various strategies and algorithms for DTC control of Induction Motor drives in recent years. The basic principles of various techniques are presented along with its efficacies and limitations. This paper focused more on torque ripple reduction. The simulation results obtained with DTC-SVPWM shows that better speed and torque responses with reduced torque ripples can be achieved. The DTC can be made less parameter dependent with online parameter estimation using IoT. Still there is a lot of scope for the development of intelligent DTC strategies.

\section{REFERENCES}

1. Ravi Hemantha Kumar, Atif Iqbal, Natesan Chokkalingam Lenin, "Review of recent advancements of direct torque control in induction motor drives - a decade of progress “, IET Power Electron., 2018, Vol. 11 Iss. 1, pp. 1-15.

2. S. Hussain, H. Khan and M. A. Bazaz, "Neural Network Observer for Sensorless Direct Torque Controlled Induction Motor Drive," 2018 International Conference on Power Energy, Environment and Intelligent Control (PEEIC), Greater Noida, India, 2018, pp. 835-840

3. V. P. Muddineni, S. R. Sandepudi and A. K. Bonala, "Simplified finite control set model predictive control for induction motor drive without weighting factors," 2016 IEEE International Conference on Power Electronics, Drives and Energy Systems (PEDES), Trivandrum, 2016, pp. 1-6..

4. A. Dannier, A. Del Pizzo, L. P. Di Noia and S. Meo, "Integral sliding-mode direct torque control of sensorless induction motor drives," 2017 IEEE International Symposium on Sensorless Control for Electrical Drives (SLED), Catania, 2017, pp. 243-248.

5. Abdelkarim Ammar, Abdelhamid Benakcha, Amor Bourek," Closed loop torque SVM-DTC based on robust super twisting speed controller for induction motor drive with efficiency optimization", International Journal of Hydrogen Energy, Volume 42, Issue 28, 13 July 2017, Pages 17940-17952.

6. T. G. Habetler, F. Profumo, M. Pastorelli, and L. M. Tolbert, "Direct Torque Control of Induction Machines using Space Vector Modulation," IEEE Trans. Ind. Appl., vol. 28, no. 5, pp. 428-436, 1992..
7. N. Muley, A. Chabukswar, R. Sarkar, K. V. P. Kumar and T. V. Kumar, "Reduction of torque and flux ripples in Direct Torque controlled five-phase induction motor drive based on instantaneous voltage control technique," 2016 IEEE International Conference on Power Electronics, Drives and Energy Systems (PEDES), Trivandrum, 2016, pp. 1-5

8. R. K. Behera and S. P. Das, "High performance induction motor drive: A dither injection technique," 2011 International Conference on Energy, Automation and Signal, Bhubaneswar, Odisha, 2011, pp. $1-6$

9. S. Potturi and R. P. Mandi, "Critical Survey on IOT Based Monitoring and Control of Induction Motor," 2018 IEEE Student Conference on Research and Development (SCOReD), Selangor, Malaysia, 2018 , pp. 1-6.

10. M. H. Holakooie, M. Ojaghi and A. Taheri, "Modified DTC of a Six-Phase Induction Motor With a Second-Order Sliding-Mode MRAS-Based Speed Estimator," in IEEE Transactions on Power Electronics, vol. 34, no. 1, pp. 600-611, Jan. 2019

11. S. Anil Chandrakanth, N. Kumar, T. R. Chelliah and S. P. Srivastava, "Sensitivity analysis of model-based controller applied to loss minimization of induction motor," 2012 IEEE 5th India International Conference on Power Electronics (IICPE), Delhi, 2012, pp. 1-5

12. M. Vasudevan - R. Arumugam • S. Paramasivam, "Development of torque and flux ripple minimization algorithm for direct torque control of induction motor drive", Springer-Verlag 2005,pp 41-51.

\section{AUTHORS PROFILE}

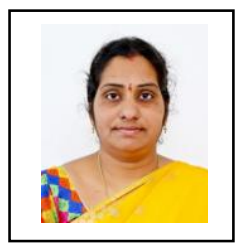

Mrs. Sudharani Potturi obtained her bachelor's degree in Electrical and Electronics Engineering and Masters Degree in Power Electronics and Industrial Drives. Currently pursuing Ph.D in the field at REVA University. She has 16 years of teaching experience and her areas of interests are Power Electronics and

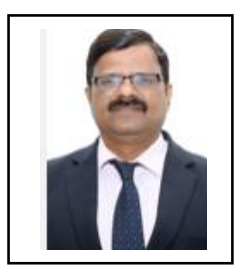

Dr. Rajashekar P. Mandi, Director, School of Electrical and Electronics Engineering, REVA University, holds Doctorate from NITK, Surathkal in the area of "Power and Energy". He has five year of teaching experience. Prior to venturing into the field of academia, he has worked in Central Power Research Institute (CPRI) of for more area of Power system simulation, Power distribution than 26 years in Energy conservation, Energy audit in thermal \& hydro power plants, process industries, institutions \& buildings, Power system, Renewable energy systems, His research interests include smart grid, microgrid, LVDC, hybrid power system, renewable energy systems, energy conservation, strengthening of electrical distribution systems, electrical safety, power quality. He had published more than 141 technical papers in International \& Indian Journals, Conferences \& Seminars in the field of energy conservation, power quality, LED lighting system and renewable energy systems 